\title{
Employee Perspectives of Working Remotely During the COVID-19 Pandemic: Ministry of Education in the United Arab Emirates
}

\author{
Rawdha AlMarar $^{1} \quad$ Amani Alkhodari $^{1^{*}} \quad$ Dina Y. Atia $^{1} \quad$ Satti Mohamed $^{1} \quad$ Raed M Shubair $^{1,2}$ \\ 1.Ministry of Education, Abu Dhabi, UAE \\ 2.Massachusetts Institute of Technology (MIT), Cambridge, MA 02139, US \\ * E-mail of the corresponding author: amani.alkhodari@moe.gov.ae
}

\begin{abstract}
The global outbreak of the COVID-19 pandemic has altered the way work is performed, shifting it from conventional offices into virtual environments. The United Arab Emirates (UAE) has attempted to face and embrace these challenges nationally in a supportive and coordinated manner, offering reasoned solutions with the wise vision and continuous support of its leadership. This paper examines the transition of work at one of the most influential entities in the UAE; the Ministry of Education (MOE). The purpose here is to highlight the impact of this transition on employees of all levels within the ministry. This paper evaluates the experience of remote working at the MOE from employees' perspectives by assessing the following key factors: MOE readiness, employee satisfaction, and employee productivity. For this purpose, a survey of around 1,500 employees was conducted and analyzed, where each of these three key factors was broken down into several contributing factors. This paper offers insights regarding the activation of remote working systems for employees in response to unanticipated incidents, highlighting a variety of factors which contribute to their readiness, satisfaction, and productivity. This study analyzes the value and originality of MOE remote working practices and their impact on the wider community.
\end{abstract}

Keywords: Working remotely, telework, remote work, virtual environments, COVID19

DOI: $10.7176 / \mathrm{EJBM} / 12-33-03$

Publication date: November $30^{\text {th }} 2020$

1. The Transition to Remote Working Practices: A Business Mindset Emerging During COVID-19

An increasing reliance on information technology infrastructures which advance continuously in an increasingly fast-paced employment environment is altering the temporo-spatial concepts of work performance. Consequently, businesses mindsets are beginning to shift into alternative workplace environments, in particular working remotely. The concept of virtual environments or teams is not a new one for global industries, given the availability of the Internet since the $1980 \mathrm{~s}$ and the subsequent $21^{\text {st }}$ century advancements in associated technologies. To progress in this area, it is clearly important to gain an understanding of the most recent remote worldwide implementations. According to a global survey conducted by the International Workplace Group (IWG) in January 2019 on over 15,000 professionals of 80 nationalities, $62 \%$ of businesses currently have a flexible workplace policy and over half of the employees are working remotely for at least 2.5 days a week (Dixon, 2019). As per the IWG study, among the main drivers of flexible working are national or international business expansion, an interest in reducing capital or operational expenses, and a desire to consolidate business portfolios. On the other hand, challenges and obstacles addressed by the IWG report include changing long-standing non-flexible organizational cultures and understanding the benefits of remote working, as well as major concerns regarding privacy and technology requirements.

\subsection{The Response of the United Arab Emirates and the Ministry of Education to COVID-19}

In early 2020, the World Health Organization (WHO) declared the Coronavirus (COVID-19) outbreak to be a pandemic and identified social distancing as a key contributor in preventing wide and rapid spread of the virus (World Health Organization, 2020). Consequently, global businesses and organizations began to alter their working practices by requiring their employees to work remotely.

In the United Arab Emirates (UAE), a number of measuring have been put in place aimed at addressing possible concerns arising from these issues, including health, food, education, and security in the country. Employees across all industries were empowered and trusted to support the country in such times. A remote working system was initially launched in the public sector for employees vulnerable to COVID-19 infection, including mothers, pregnant women, elderly people, people of determination, and those with health issues that potentially compromise their immune system. This system was then expanded to include most other public sector employees in ministries, authorities, and federal institutions, with similar regulatory guidelines presented for companies across the private sector. A maximum of $30 \%$ of the workforce of each concerned entity was permitted to be physically present in the office, so as to maintain hygiene and physical distancing. Those employees whose 
work did not require their presence in the office were obliged to work from home. Besides, a daily sterilization program was initiated for a specific duration subject to review and renewal (Ministry of Interior in the United Arab Emirates, 2020).

Within the Ministry of Education (MOE), a business continuity team have undertaken the responsibility of guiding all departments and their employees towards a smooth transition into remote working and addressing any challenges arising from this. Following official sources of information such as the Ministry of Health and the National Crisis and Emergency Management Authority (NCEMA), specific health and safety precautions were regularly communicated in order to safeguard the safety and wellbeing of all employees. Another key decision taken by the MOE in coordination with the NCEMA was to divide employees of each department into sub-groups, ensuring such sub-groups have no physical interaction either in the office or during remote working, and allowing employees within each individual sub-group to be present in the office as and if needed. This likewise aimed to safeguard the health and safety of all employees across the ministry without disruption of necessary work.

This paper discusses the transition within the MOE to remote working from the perspective of its employees. It describes the approach followed for the measurement of the three key factors selected as essential elements of the remote work experience, namely MOE readiness, employee satisfaction, and employee productivity. A measurement of departmental readiness is also presented in order to showcase needs which were captured and addressed. The paper concludes with a summary of challenges and advantages as well as proposed future actions.

\section{Previous Studies Regarding the Impacts on Employees Working Remotely}

This section briefly reviews the literature surrounding the topic of remote working with the role of the employees as its main point of focus. It addresses the impacts of remote work on concerned employees and organizations and aims to highlight future research work which might potentially develop understanding of this field.

The practice of remote working may impact employees involved in the experience in ways which can eventually affect the organization. On the individual level, the most commonly reported positive impacts include reduction in transport time and cost (Baruch \& Nicholson, 1997), flexibility in planning working hours (Reinsch, 1997), and increased levels of overall productivity (Caudron, 1992). On the organizational level, positive impacts may include lower absenteeism (Fitzer, 1997), office rental savings (Apgar, 1998), quicker responsiveness to unexpected events like natural disasters (Eldib \& Minoli, 1995), increased productivity (Trembly, 1998), and better utilization of information systems (Pinsonneault \& Boisvert, 1999).

On the other hand, one frequently sited impact of working from home is the intrusion of workload into employees' personal life and domains (Nilles, 1994). As per (Day, Barbar, \& Tonet, n.d.), technology may be responsible for disruptions in work-life balance, interruptions of workflow, and exacerbation of employee stress. This conceptualization remains however somehow underdeveloped, and additional research is needed to examine links in this field. A study on employees across Australia revealed that working long hours is regarded as an inherent element of working from home, contributing to the dissatisfaction of employees with the resulting worklife balance (Dockery \& Bawa, 2014). Similar opinions were reported in a study by the National College of Ireland which investigated employees' perceptions of working from home and work-life balance. Although the Irish employees were happy with the overall outcomes of working from home, they did report negative impacts on life outside of work such as difficulties in disconnecting themselves from work and enjoying high-quality personal time once daily work requirements had been completed (Muldoon, 2014).

In the light of these effects of remote working, one interesting area in literature is the extent to which employees are willing to commute if given the opportunity to instead telecommute. A paper investigating the relationship between telecommuting and commuting time suggested that the prospect of being able to work from home resulted in workers being willing to accept 5\% longer commuting times on average (De Vos, Meijers, \& van Ham, 2018). That is, workers are more flexible in accepting jobs located at a longer distance from their homes if they have also the option of working from home on one or more days per week. The study also suggested that telecommuting policies may be effective in reducing the effects of congestion and transport-related emissions at traditional commuting times.

One reported approach concerns the question of teleworker motivation - the reasons why teleworking may appeal to some, the goals that they hope to achieve in doing so, and what facets of remote working may constitute potential problems. Commencing a research study with employee motivation may thus assist in understanding their behavior, thoughts, strategy, and enthusiasm about the work they perform, in a way which will also reflect upon the overall performance and productivity of the entity they belong to. Another potential research area in remote working is the status of telework at home and how its significance is perceived differently between genders. According to a study by (Haddon, 1999), women were more interested in telework because it facilitated childcare, yet were more involved in part-time work. Men, on the other hand, aspired for full-time work and their concerns leant more towards the exemption from social life around the household. Gender perceptions and the nature of work are thus two dimensions which may be further explored by future studies.

Defining a suitable research methodology is an important component of any conducted research study. In a 
study by (Nakrošienè, Bučiūnienè, \& Goštautaite, 2019), a deductive approach was followed to statistically test relationships between telework factors and telework outcomes, taking into consideration previous studies by (Pérez, Sánchez, \& Carnicer, 2003) and (Gurstein, 2001). Factors studied included the trust and support of supervisors, the ability to take care of family members (Ammons \& Markham, 2004) (Johnson, Andrey, \& Shaw, 2007), the possibility of accessing organizational documents from home (Madsen, 2003), and the opportunity to save expenses for travel (Morgan, 2004). Broad outcomes were overall satisfaction with telework (Pratt, 1999), perceived advantages of telework, subjective career opportunities, and self-reported productivity (Golden \& Veiga, 2008). Findings also showed that the trust and support of one's supervisor was one of the most significant factors impacting different telework outcomes.

It should be noted at this stage that the Ministry of Education study in this paper follows the approach of data collection through a survey for its employees across the ministry accompanied by qualitative analysis, as will be illustrated below.

\section{Study and Assessment of Factors Affecting MOE Employees Working Remotely}

MOE leadership aim to ensure that all internal actions taken benefit employees. Gathering feedback from all departments and working towards finding solutions and satisfying needs is thus considered a priority. It was considered essential during the transition to remote work that voices of employees in all departments were heard and any concerns addressed. In order to gain the necessary information on the impacts of such a transition on MOE employees and evaluate their overall experience, a ministry-wide survey was therefore conducted.

During this study, three key factors were measured to evaluate the experience of remote working at the MOE: MOE readiness, employee satisfaction, and employee productivity. Quantitative data necessary for the analysis was gathered from a survey of around 1,500 employees representing all sectors and departments at the ministry. This approach of survey analysis was selected due to its ability to test concepts and assess opinions, thoughts, and feelings to uncover answers and base decisions on objective information. This survey thus served the intended purpose of establishing an overall level of satisfaction among employees and reflecting their overall attitudes.

\subsection{Measurement of Ministry Departments' Readiness for Remote Work}

It was necessary, prior to surveying MOE employees, to gain insights into the ministry readiness to remote working and the way it was measured across all departments. Measurements conducted indicated that $75 \%$ of MOE departments were in a state of readiness for the experience when the pandemic began, whilst $25 \%$ required support for the transition. Accordingly, a team was assigned to establish the shared requirements between all departments in order to increase these readiness percentages. The two most common requirements were: access to systems/documents from home (31\% of overall requirements), and lack of reliable laptops ( $25 \%$ of requirements). The remaining $44 \%$ of requirements included SIM cards, MS Teams training, and a need for physical presence in the office or for service automation. As these requirements were then gradually addressed, percentages across most sectors increased.

\subsection{Survey Design in Alignment with Key Impact Factors}

The survey was created using Microsoft Forms and circulated by the Government Communication department to all employees in the ministry to obtain their feedback in three categories aligning with the three aforementioned factors: MOE readiness, employee satisfaction, and employee productivity. An additional category was added to the survey, and titled 'Challenges', to address the challenges employees have been facing since the beginning of the remote working experience.

Survey items were designed to reflect contributory factors contributing to each category so as to assist in the accurate assessment of the overall experience of remote working at the ministry. Items that cover factors relating to MOE readiness mainly concerned: provision of technical needs (laptops, SIM cards, office phone call transfer, etc.), access to systems and shared documents, and IT staff support. Items that cover factors relating to employee satisfaction mainly concerned: leadership trust and support, and financial savings. Items that cover factors relating to employee productivity mainly concerned: sources of distraction, interaction with co-workers, physical, mental and social wellbeing, and - as previously - leadership trust and support. Information regarding gender, age, and number of children at home were considered as variables in this analysis. Appendix A lists the main survey areas used to measure and address each key category.

\subsection{Analysis of Employee Feedback and the Key Impact Factors}

Around 1,475 employees responded to the survey out of 1,695 employees, which represents an $87 \%$ response rate. These responses were analyzed according to the three abovementioned factors. Starting with MOE readiness, the survey showed that on average, around $82 \%$ of respondents received technical support, access to the necessary systems and shared folders, and were supported by the IT team when needed (错误!未找到引用源。1). This percentage of support reported by employees was reflected in the high percentage of respondents who evaluated 
the MOE as ' $80 \%-100 \%$ ready for remote working' (Figure 2 ).

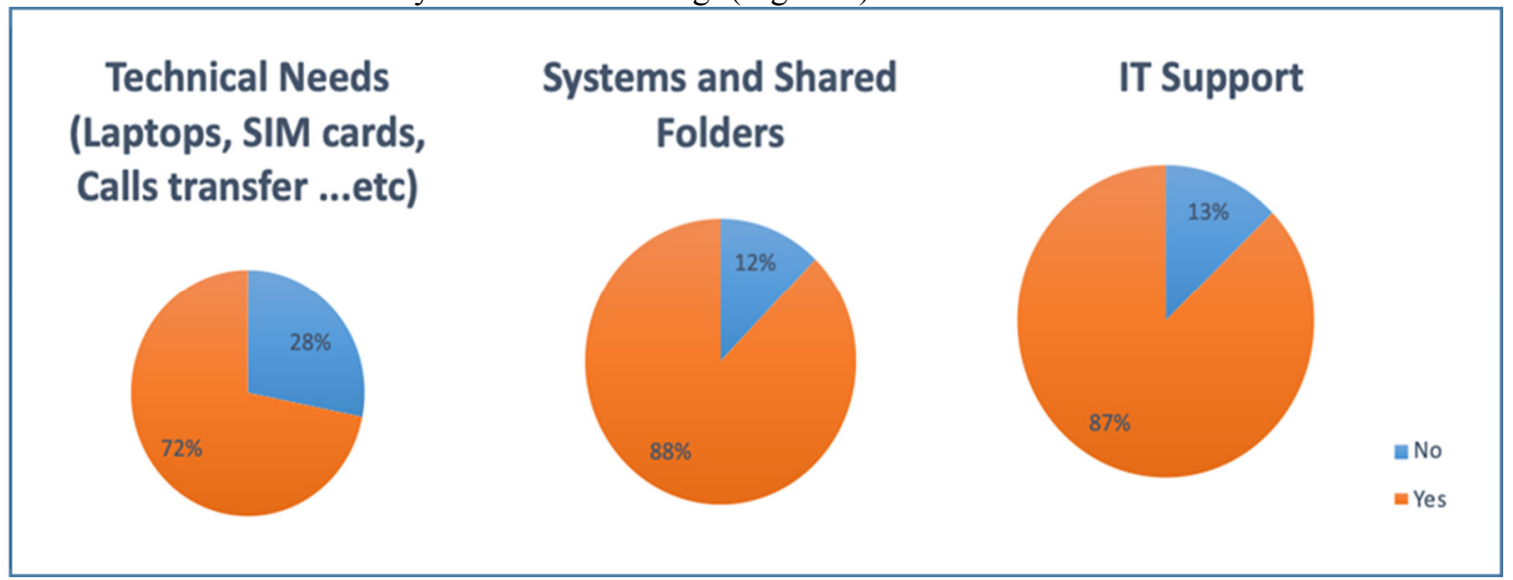

Figure 1. Factors Contributing to Readiness

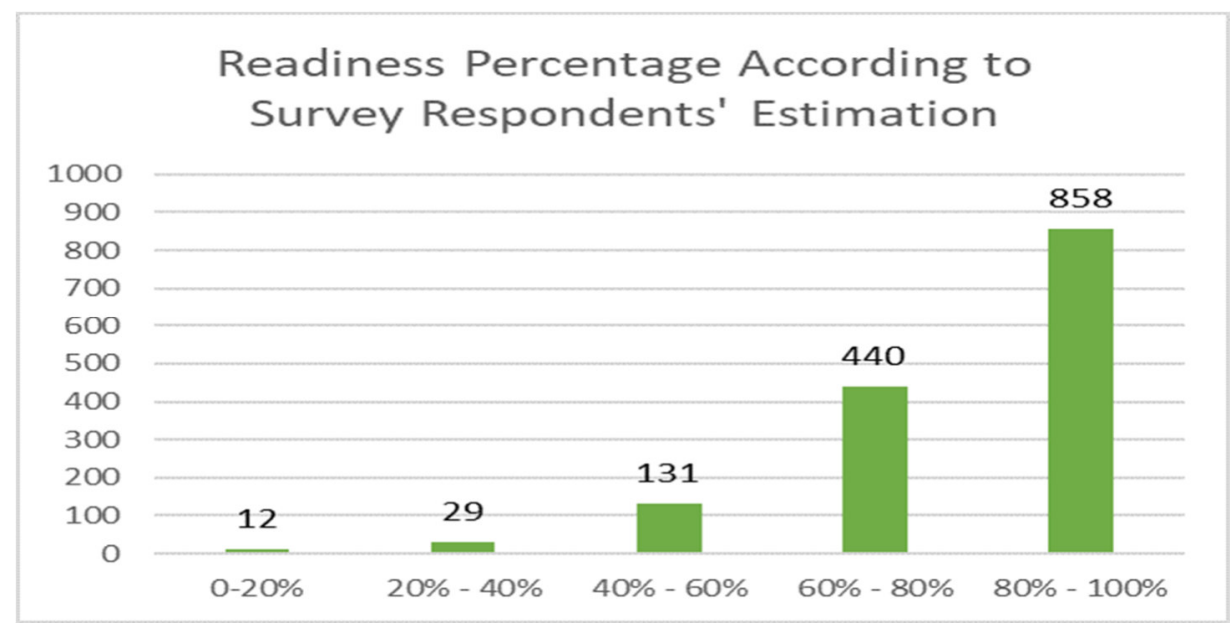

Figure 2. Readiness Percentage According to Survey Respondents' Estimation

In the area of employee satisfaction, $52 \%$ of respondents reported themselves as satisfied with their home working arrangement/environment (Figure 3). Around 70\% of respondents were most satisfied by the fact of not needing to commute/travel to work (Figure 4). This potentially explains why $72 \%$ of respondents also reported being able to save more while working remotely (Figure 5). On the other hand, $45 \%$ of employees reported that they found it harder to maintain work and life balance whilst working at home. Figure 6 shows that most of those who felt strongly in this regard were female employees $(65 \%)$ who may have other home commitments beside work duties, which possibly explains their lower percentage of satisfaction on work-life balance while working from home.

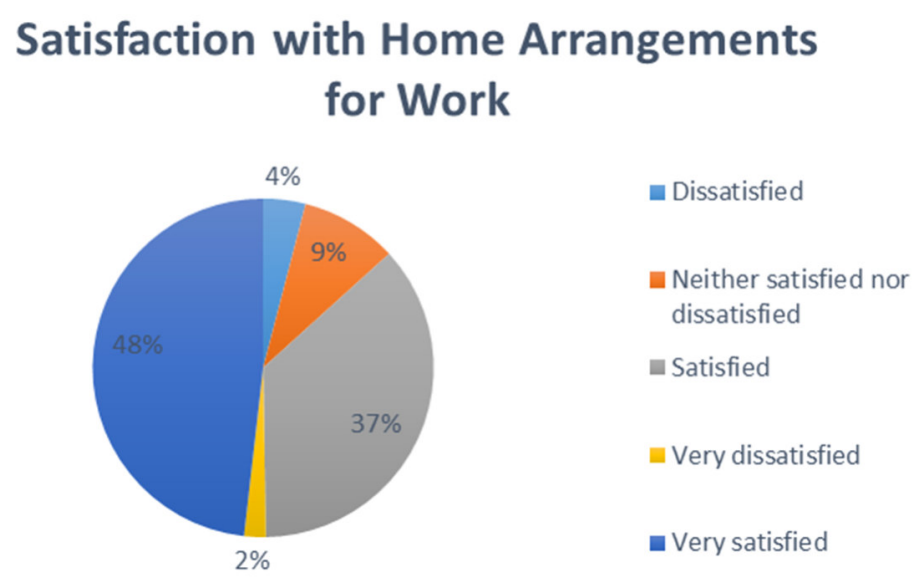

Figure 3. Satisfaction with Home Arrangements for Work 


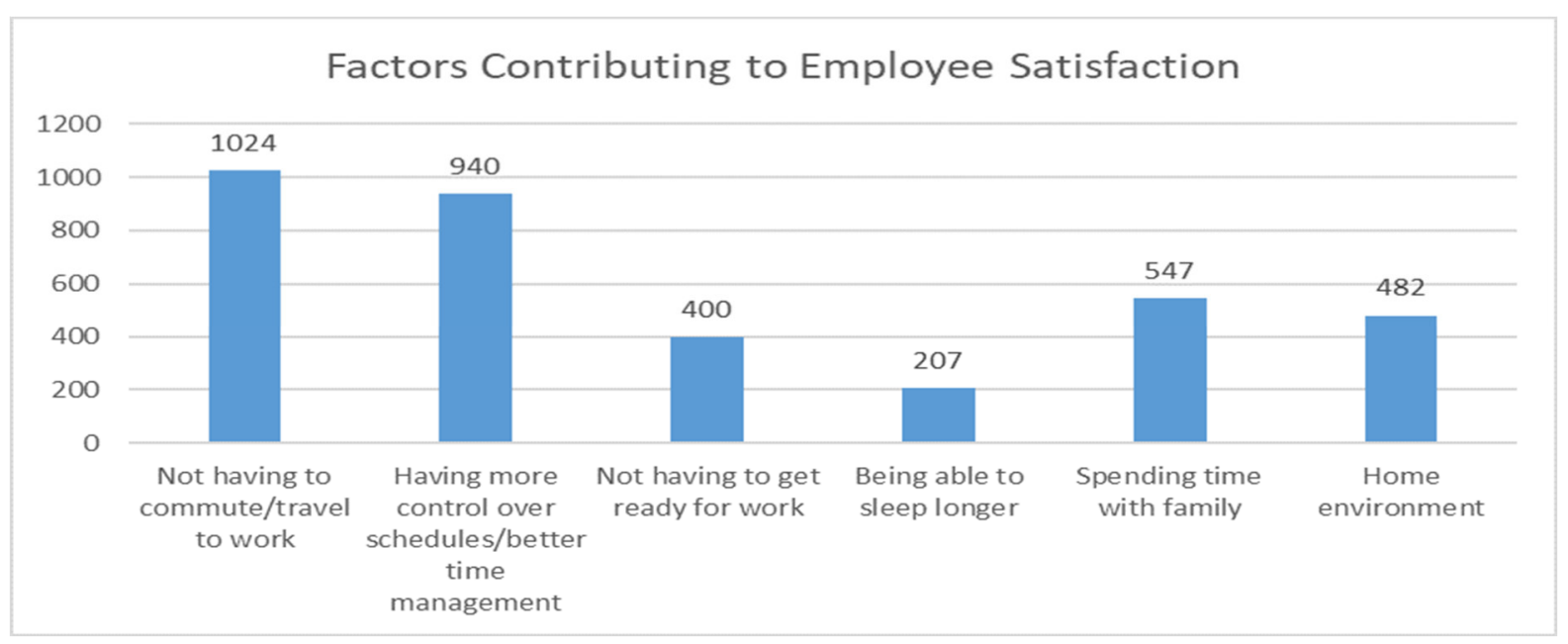

Figure 4. Factors Contributing to Employee Satisfaction

\section{Employee Savings During Remote Work}

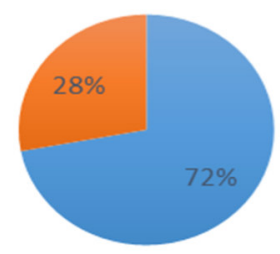

Save more

- Spend more

Figure 5. Employee Savings During Remote Work

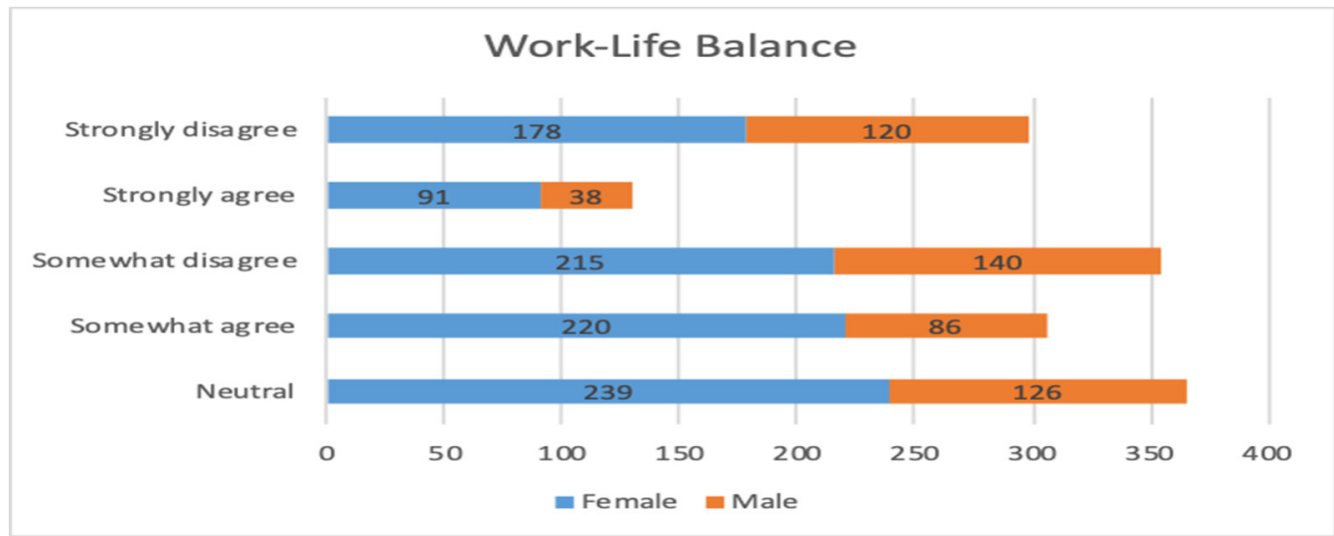

Figure 6. Employee Opinions Regarding Work-Life Balance

Finally, in the area of employee productivity, which was measured by questioning employees regarding their number of daily productive working hours, it was found that around 58\% of respondents reported working 7 or more productive hours (Figure 7). It was also notable here the extent to which leadership support and trust impacted productivity, with $68 \%$ of respondents reporting this as a positive factor (Figure 8 ). $34 \%$ of respondents also reported reduced face-to-face interaction with co-workers as increasing their work productivity, while that of a further $56 \%$ was reported as unaffected by this factor (Figure 9 ). 


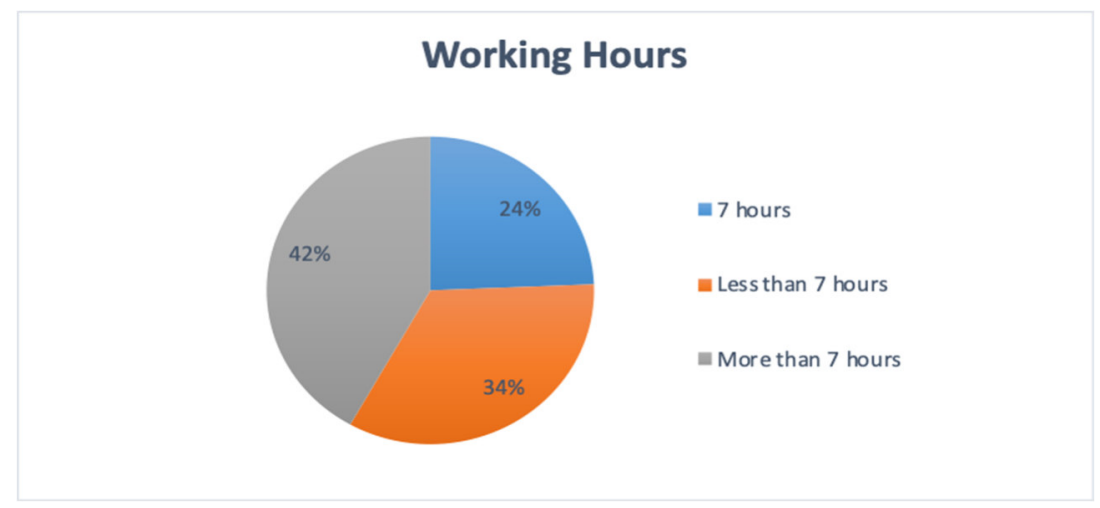

Figure 7. Productive Working Hours as Reported by Employees

\section{Impact of Leadership Support and Trust on Productivity}

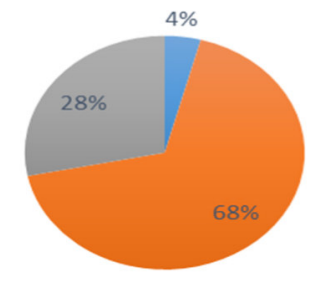

Negatively affecting performance

E Positively affecting performance

Unaffected

Figure 8. Impact of Leadership Support and Trust on Productivity

\section{Impact on Productivity of Reduced Face-to-face Interaction with Co- workers}

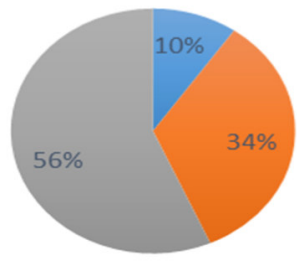

Negatively affecting performance

- Positively affecting performance

n Unaffected

Figure 9. Impact on Productivity of Reduced Face-to-face Interaction with Co-workers

Aside from these key factors, an additional question was listed in order to measure the impact of working remotely on 4 further items: focus, health/physical wellbeing, stress/mental wellbeing, and social welling. Figure 10 illustrates these findings on a scale from0-5. Working remotely can be seen to have positively affected the majority of respondents in terms of focus, health/physical wellbeing, and mental wellbeing. However, it had a less marked effect on social wellbeing probably due to reduced face-to-face interactions. Overall, $70 \%$ of the respondents were satisfied with the remote working experience and recommended its retention as a future work option Figure 11). 


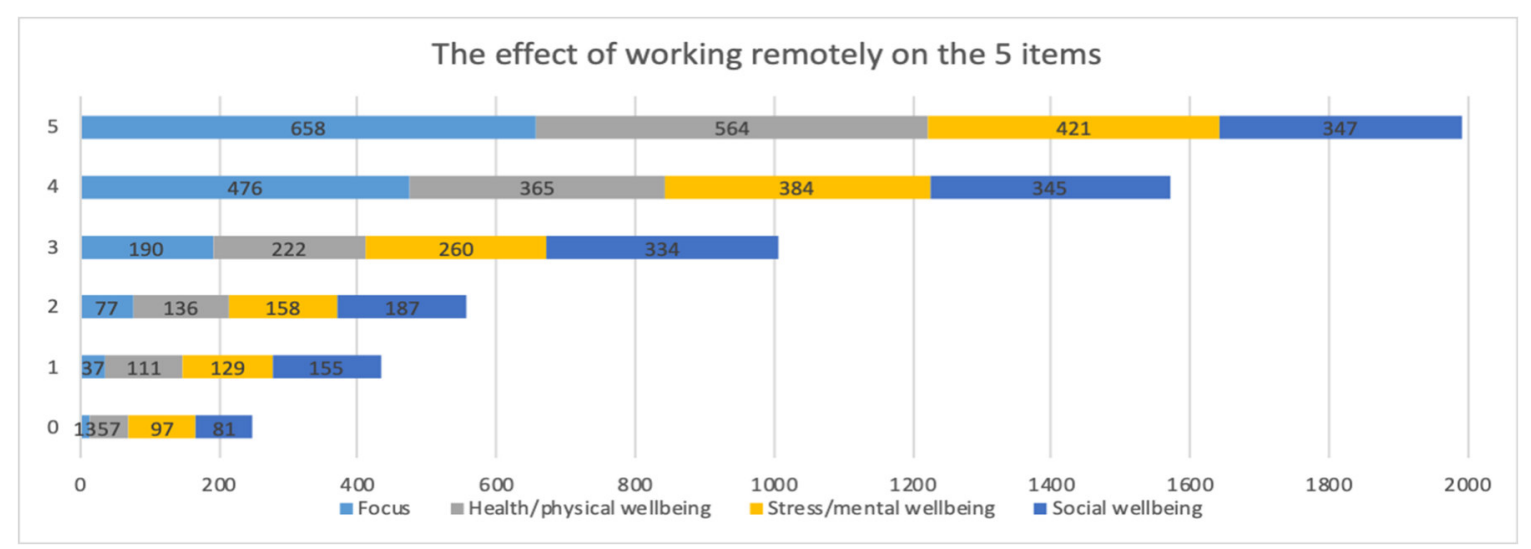

Figure 10. The Effect of Working Remotely on Four Items

\section{Employee Recommendation for Remote Working as a Future Option}

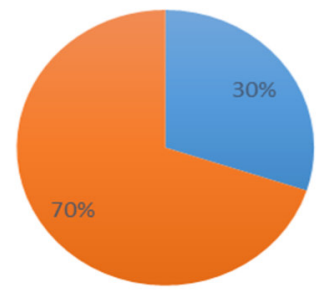

Figure 11. Employee Recommendation for Remote Working as a Future Option

Regarding challenges faced, the most common issues faced by the employees appeared to be technical problems with $23 \%$, as well as longer working hours with $18 \%$. Around $21 \%$ of respondents reported that they face no challenge in the experience (Figure 12).

\section{Challenges of working remotely}

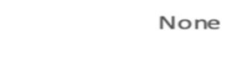

longer work hours

(Isolation Vlack of social interaction) I don't feel connected with the team

Problem solving takes long er when nucolleagues aruund to discuss

Unappropriate physical workplacelErgonomics issues

Lack of mot ivation due to peer social isolation

Distractions and interruption

Line ma nager support is not enough

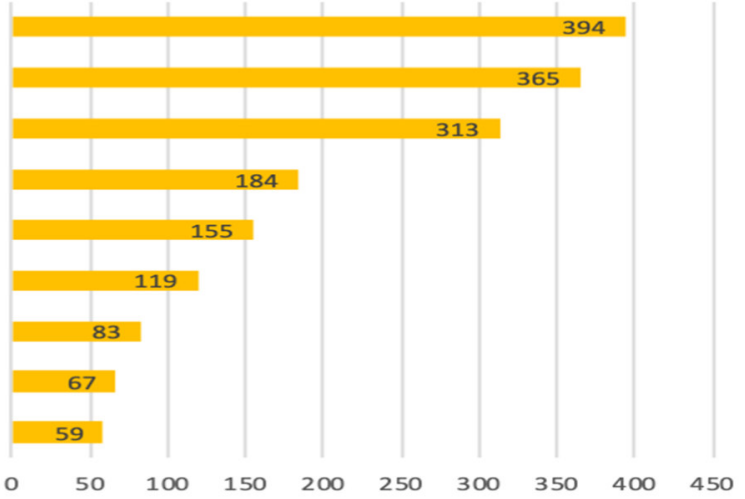

Figure 12. Challenges of Remote Working Faced by Employees

From a managerial perspective, the most challenging issue reported in the survey by line manager respondents was the maintenance of good communication in order to ensure business continuity $(37 \%)$, whereas a number of line managers had no issues to report (26\%). As Figure 13 illustrates, tracking employees' tasks and performance was not a major challenge for managers and leaders, as leadership support and trust was the main impetus behind the remote working experience at the MOE. About $84 \%$ of respondents reported themselves as satisfied or very satisfied with the support and trust received from their line managers (Figure 14), which had the effect of improving their overall performance and productivity, as previously shown in Figure 8. 


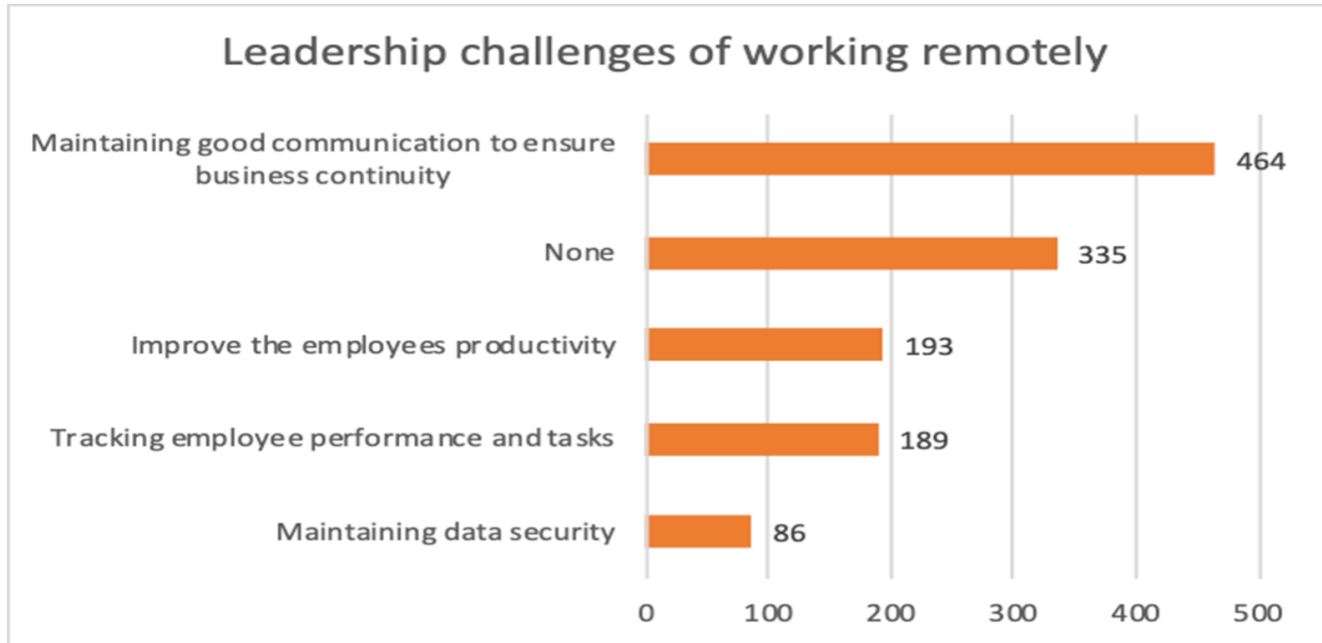

Figure 13. Challenges Faced by Leadership When Working Remotely

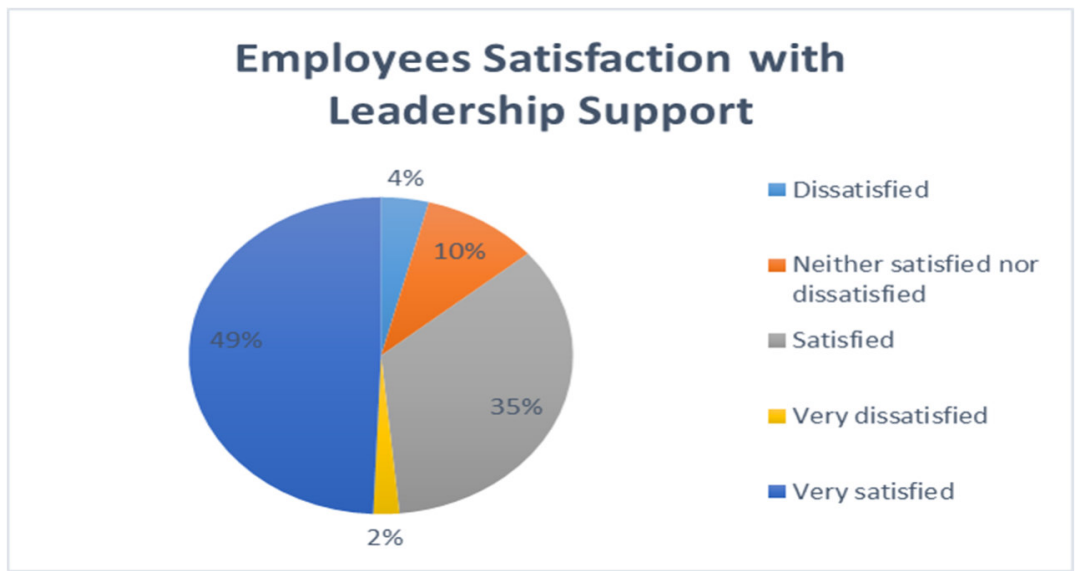

Figure 14. Employee Satisfaction with Leadership Support

\section{Challenges Facing MOE Remote Workers and the Accompanying Advantages}

Employees at work are accustomed to encountering several challenges throughout their working career, particularly where new concepts are introduced, or any type of disruption occurs. Individuals naturally respond differently to such events, and it is principally the responsibility of employers and managers to ensure such changes take place in an ordered way. The MOE leadership strongly emphasized throughout this process that the transformation of those challenges involved in remote working into advantages was crucial to the success of the overall experience.

One challenge faced by the MOE during the transition was the shift for employees into providing services and responding to clients using virtual environments. This challenge was turned into an opportunity for speeding up the process of making services fully electronic, which has led to the establishment and training of a team of volunteers to assist all employees in adapting to the new remote system and also help in solving problems and spreading awareness. In addition to this, employees were trained virtually on the use of different online platforms during the remote work period, which contributed significantly to tackling those challenges that were related to technical issues. Online training has indicated which groups require additional training and has also initiated the process of gaining responses from trainees aimed at improving this experience.

Overall, the adoption of remote working by the ministry has proven advantageous during these critical times. A new work model that incorporates remote work policies and procedures would have a strong potential for reducing financials through lowering costs associated with space rental, commuting, and time. Besides, this transition has expedited the testing and usage of existing developed platforms invested in by the ministry, such as learning by distance for students, virtual training, virtual libraries, and other electronic services.

\section{Recommendations for Additional Types of Analysis Relevant to Remote Workers}

As for future work, this study potentially forms a basis for further research incorporating deeper statistical analysis, which would necessitate the collection of numerical data points. Transforming such factors into study variables and examining their correlation would add significantly to this study, and projects such as the building of a 
regression model that could predict future trends in remote working at the ministry could improve future foresight plans. Additional research could also potentially explore specific topics relevant to remote working. These topics could include the psychological effect of teleworking on employees and their families, behavior patterns of employees working from home and their impact on job performance, or the role of Artificial Intelligence in a remote work revolution.

In addition, the enlargement of scale could expand the study of working remotely, or similar studies, across all ministries and federal entities in the UAE. This is admittedly an optimistic outlook, yet nevertheless achievable should teams representing each participating entity be willing to collaborate under the supervision and guidance of an appropriate research institution.

\section{Positive Employee Insights: A Drive Towards Future Remote Work Options}

In responding to the COVID-19 pandemic with the support of the UAE leadership, the Ministry of Education, as a leading entity in the country, was able to activate remote working for its employees utilizing virtual environments. This paper evaluates the experience of working remotely at the ministry from the perspective of employees by assessing the following key factors: MOE readiness, employee satisfaction, and employee productivity. A survey of around 1,500 employees was analyzed, where each of these three key factors was broken down into several contributing factors. Provision of technical needs and access to systems and documents from home explained the rise in percentages of readiness reached at the ministry level, exceeding $90 \%$ in around $60 \%$ of all sectors. Around $69.4 \%$ of employees were very satisfied with the experience of working remotely, with the lack of requirement to commute to work being the most important factor impacting their satisfaction. Most employees reported working more than 7 hours on average, with $68 \%$ believing leadership trust and support to be positively affecting their performance and productivity. Technical problems were reported as the most challenging issues faced by employees, whereas maintaining good communication to ensure business continuity was found to be the main challenge for managers. Based on the advantages of working remotely that have been captured and experienced by employees during this period, it is potentially valid to say that working remotely might reasonably be considered as a practical option in the future.

\section{Acknowledgement}

The authors of this paper would like to acknowledge the tremendous efforts of the internal teams of the Ministry of Education and the support of the management in facilitating the transition and enabling their employees, and granting approval to share the overall experience.

\section{References}

Ammons, S., \& Markham, W. (2004). Working at home: experiences of skilled white-collar workers. Sociological Spectrum, 24(2), 191-238.

Apgar, M. (1998). The Alternative Workplace: Changing Where and How People Work. Harvard Business Review, 121-136.

Baruch, Y., \& Nicholson, N. (1997). Home, Sweet Work: Requirements for Effective Home Working. Journal of General Management, 15-30.

Caudron, S. (1992). Working at Home Pays Off. Personnel Journal, 40-49.

Day, A., Barbar, L., \& Tonet, J. (n.d.). Information Communication Technology and Employee Well-Being: Understanding the "iParadox Triad" at Work. ICT, Stress, \& Well-being, 1-51.

De Vos, D., Meijers, E., \& van Ham, M. (2018, July 5). Working from home and the willingness to accept a longer commute. The Annals of Regional Science, 375-398.

Dixon, M. (2019, March). THE IWG GLOBAL WORKSPACE SURVEY. Welcome to Generation Flex - the employee power shift.

Dockery, A. M., \& Bawa, S. (2014). Is Working from Home Good Work or Bad Work? Evidence from Australian Employees*. AUSTRALIAN JOURNAL OF LABOUR ECONOMICS, 17, 163-190.

Eldib, O., \& Minoli, D. (1995). Telecommuting. Boston: Artech.

Fitzer, M. (1997, Jan 1). Managing from Afar: Performance and Rewards in a Telecommuting Environment Compensation and Benefits Review. 65-73.

Golden, T., \& Veiga, J. (2008). The impact of superior-subordinate relationships on the commitment, job satisfaction, and performance of virtual workers. The Leadership Quarterly, 19(1), 77-88.

Gurstein, P. (2001). Wired to the World, Chained to the Home: Telework in Daily Life.

Haddon, L. (1999). Approaches to Understanding Teleworking. London School of Economics.

Johnson, L., Andrey, J., \& Shaw, S. (2007, April). Mr. Dithers Comes to Dinner: Telework and the merging of women's work and home domains in Canada. Gender, Place and Culture, 14(2), 141-161.

Madsen, S. (2003). The effects of home-based teleworking on work-family conflict. Human Resource Development Quarterly, 14(1), 35-58. 
Ministry of Interior in the United Arab Emirates. (2020, April 4). Retrieved 20 2020, from https://www.moi.gov.ae/en/media.center/News/040101.aspx

Morgan, R. (2004). eleworking: an assessment of the benefits and challenges. European Business Review, 16(4), 344-357.

Muldoon, N. (2014). An Investigation into employee's perceptions of working from home and how this impacts work - life balance. National College of Ireland.

Nakrošienè, A., Bučiūnienè, I., \& Goštautaitè, B. (2019). Working from home: characteristics and outcomes of telework. Inernational Journal of Manpower, 40, 87-101.

Nilles, J. (1994). Making Telecommuting Happen. New York.

Pérez, M., Sánchez, A., \& Carnicer, M. (2003). The organizational implications of human resources managers' perception of teleworking. Personnel Review, 32(6), 733.

Pinsonneault, A., \& Boisvert, M. (1999). The Impacts of Telecommuting on Organizations and Individuals: A Review of the Literature. Telecommuting and Virtual Offices.

Pratt, J. (1999). Selected communications variables and telecommuting participation decisions: data from telecommuting workers. The Journal of Business Communication, 36(3), 247-254.

Reinsch, L. (1997). Relationship Between Telecommuting Workers and their Managers: An Exploratory Study. The Journal of Business Communications, 343-369.

Trembly, A. (1998). Telecommuting Productively. Beyond Computing, 42-44.

World Health Organization. (2020). Retrieved April 2020, from https://www.who.int/healthtopics/coronavirus\#tab=tab_1

Appendix A. Survey Categories and Items Measuring Study Key Factors

Survey Categories

MOE Readiness

Employee Satisfaction

Employee Productivity

\section{Items}

- MOE did/did not provide me with the necessary technical needs for working by distance (laptops, SIM cards, phone, etc.)

- I do/do not have access to the systems and shared documents

- IT staff are/are not available to support me on a timely basis

- I am/am not satisfied with my current work from home arrangement

- It is/is not hard to maintain a balance between work and life when working from home

- I am/am not satisfied with leadership trust and support

- Since the beginning of the remote working period, I have been saving/spending more

- $\quad$ I am required to send my activity reports to my manager on a $X$ basis

- $\quad$ On average, I work daily for $X$ number of hours

- Not being in the office, I do/do not find that less face-to-face interaction with co-workers has increased my productivity and job performance

- The most challenging issues in my daily work from home are...

- Being a line manager/in a leadership position, the most challenging aspect in remote working from managerial perspective is...

- I do/do not suggest continuing the application of the remote working system as a work option available in the future 